\title{
BEYOND THOREAU: LITERARY RESPONSE TO NATURE
}

Guest edited by Wang Ning 